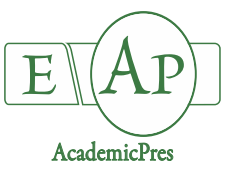

Chu X et al. (2021)

Notulae Botanicae Horti Agrobotanici Cluj-Napoca

Volume 49, Issue 2, Article number 12244

DOI: $10.15835 /$ nbha 49212244

Research Article

\title{
Exponential fertilization on red-seed tree (Ormosia hosiei) seedlings subjected to contrasting light conditions: Do we really need intensive nutrient loading?
}

\author{
Xiuli $\mathrm{CHU}^{1,2}$, Xianyou $\mathrm{LUO}^{3}$, Zhichun $\mathrm{ZHOU}^{1 *}$ \\ ${ }^{1}$ Research Institute of Subtropical Forestry, Chinese Academy of Forestry, Zhejiang Provincial Key Laboratory of Tree Breeding, \\ 31140, Hangzhou, China; xiulic0207@163.com; zczhou_risf@163.com ("corresponding author) \\ ${ }^{2}$ Shanghai Botanical Garden, Shanghai Engineering Research Center of Sustainable Plant Innovation, 200231, Shanghai, China; \\ xiulic0207@163.com \\ ${ }^{3}$ Forestry Academy of Longquan City, Lishui 323700, China; 973619006@qq.com
}

\begin{abstract}
Exponential fertilization (EF) can feed seedlings with more nutrients than needed for growth and continuous lighting is expected to reduce the risk of loading at high application rate. In this study, red-seed tree (Ormosia hosiei Hemsley \& E. H. Wilson) seedlings were raised by EF at a low rate of $160 \mathrm{mg}$ nitrogen $(\mathrm{N})$ plant $^{-1}$ (conventional) (N-phosphorus $[\mathrm{P}]$-potassium $[\mathrm{K}], 12-9-12$ ) and a high rate of $600 \mathrm{mg} \mathrm{N}^{\mathrm{N}}$ plant ${ }^{-1}$ (intensive), which was adapted from previous studies with large-pot-seedlings. Both fertilizer regimes were nested to either of two light spectra from high-pressure sodium (HPS) and light-emitting diode (LED) sources with three replicates for each combined treatment. Seedlings subjected to the conventional regime in the LED spectrum showed better growth and greater biomass accumulation with higher leaf $\mathrm{N}$ and $\mathrm{P}$ contents than other ones. In the conventional fertilizer regime, the LED spectrum also resulted in higher photosynthesis shown by more pigments and higher N synthesis than the HPS spectrum. The HPS spectrum strengthened $\mathrm{P}$ synthesis in the intensive regime. The antioxidative activity was stimulated by a high dose of EF, hence excessive toxicity was likely induced. We recommend using the normal rate of $160 \mathrm{mg} \mathrm{N}$ plant $^{-1}$ for the culture of redseed tree seedlings with LED lighting to promote seedling quality without causing excessive nutrient toxicity.

Keywords: antioxidant; nutrient loading; nursery culture; red-seed tree; vulnerable species

\section{Introduction}

Red-seed tree (Ormosia hosiei Hemsley \& E. H. Wilson) is a large tree up to 20-30 meters tall. The natural range of habitat of red-seed tree is narrow and most current reserves are found in eastern and central China (Sun and Vincent, 2012). Its wood is used to produce top quality materials for the manufacture of furniture, which is traded all over the world. It was listed as a near-threatened species due to over-harvesting since roughly 20 years ago (World Conservation Monitoring Centre, 1998). Its natural habitat locates in lowelevation broadleaved forest where over-exploitation has continuously occurred. In recent decades, red-seed tree has been listed as an endangered species (Chu et al., 2020; Liu et al., 2011; Zhang et al., 2012). Artificial regeneration is an efficient way to regenerate natural red-seed tree populations. Culturing and planting seedling

Received: 29 Jan 2021. Received in revised form: 25 Mar 2021. Accepted: 16 Apr 2020. Published online: 29 Apr 2021.

From Volume 49, Issue 1, 2021, Notulae Botanicae Horti Agrobotanici Cluj-Napoca journal uses article numbers in place of the traditional method of continuous pagination through the volume. The journal will continue to appear quarterly, as before, with four annual numbers.
\end{abstract}


stocks can quickly fulfill the requirement of big recruitment while maintaining genetic diversity. Fertilization during nursery culture has arisen due to its benefit in strengthening nutritional reserves in red-seed tree seedlings (Chu et al., 2020).

Nursery fertilization can promote the establishment of newly planted tree seedlings because an abundant nutrient storage would feed transplanted seedlings to overcome weed competition (Wei et al., 2017; Jacobs et al., 2020). Exponential nutrient loading mostly synchronizes the pace of biomass accumulation in tree seedlings for most species (Duan et al., 2013; Wang et al., 2016). Exponential fertilization (EF) has been well documented to promote seedling quality through enhancing nutrient uptake to a level higher than needed for growth demand (Hawkins et al., 2005; Xu et al., 2019). The goal of harvesting nutrient-enriched seedlings promotes the interest to feed seedlings with EF at an applicative rate as high as possible. Trials have been successful in delivering nutrients at high rates in larch (Larix olgensis) (Duan et al., 2013; Wei et al., 2013) and spruce (Picea mariana)(Boivin et al., 2004) seedlings. Information has been scarce about EF on vulnerable species at high rates. Because endangered species are vulnerable to environmental stress, they will likely be more sensitive to over-dose of fertilizer application than other species. The high sensitivity of red-seed tree seedlings to different fertilizer regimes makes its response unclear.

Currently, most seedlings that have been tested by EF came from timber species, such as larch (Duan et al., 2013), oak (Salifu and Jacobs, 2006; Uscola et al., 2015), spruce (Salifu and Timmer, 2003), and Buddhist pine (Podocarpus macrophyllus) (Xu et al., 2019). Luxury consumption of nutrients was usually shaped within an optimum range with the upper limit of a high rate of nitrogen $(\mathrm{N})$ supply around $125 \mathrm{mg} \mathrm{N}$ plant $^{-1}$. The most intensive dose was found on Quercus ilex seedlings which ranged up to $200 \mathrm{mg} \mathrm{N}$ plant ${ }^{-1}$ (Uscola et al., 2015). These doses were used in studies with soluble fertilizers. Otherwise, controlled-release fertilizer (CRF) is a common and practical means to feed seedlings with the desired nutrient reserve for vulnerable species ( $\mathrm{Li}$ et al., 2017; Wei et al., 2017; Chu et al., 2019, 2020). The upper limit in studies using CRF for red-seed tree seedlings has been around $600 \mathrm{mg} \mathrm{N}$ plant $^{-1}$ ( Li et al., 2017; Chu et al., 2020). Although the amount of fertilizer appeared to be much higher than fertigation delivery, the active uptake was low due to limited efficiency. The formula of nutrient delivery from CRF cannot fully synchronize the dynamic of nutrient demand according to growing dynamic. Nutrient loss from bottom leakage is hard to avoid and at least partly contributed to the low efficiency of nutrient delivery (Zhu et al., 2016). Therefore, an intensive regime of EF was still detectable under the condition that nutrients were delivered by fertigation.

Compared to the condition where all light sources are given by sunlight, a lighting environment with the unique source of artificial illumination was found to increase the nutritional demand in growing seedlings (Wei et al., 2013; Zhu et al., 2016; Li et al., 2017). This is because continuous lighting promotes biomass accumulation, height growth will also be enhanced accordingly. These changes need more nutrient assimilation to fulfill the demand for synthesis and production. As a result, seedlings exposed to an extended photoperiod generally showed an enlarged appearance and uptake amount compared to those in a natural photoperiod. High-pressure sodium (HPS) lamps are one of the most common instruments used to achieve continuous lighting in greenhouse production of tree seedlings (Apostol et al., 2015; Wei et al., 2017). Further development of light-emitting diode (LED) reveals that the modification of light spectra can further promote biomass accumulation and enlarge the demand of nutrient uptake (Luo et al., 2020; Wei et al., 2020; Wei et al., 2020; Zhao et al., 2020). Compared to the HPS spectrum, the use of LED spectrum on seedlings has shown additional benefits like promoted root development and active physiology (Li et al., 2018; Luo et al., 2020; Wei et al., 2020). Therefore, the use of different light spectra in the extended photoperiod can facilitate successful feeding of red-seed tree seedlings with an intensive EF regime.

In this study, red-seed tree seedlings were raised using an intensive dose of EF with the conventional dose as the control. One LED light spectrum was tested for its combined effect on seedling response in comparison to the HPS lamp light spectrum. We hypothesize that (i) intensive nutrient loading can be effective in promoting nutrient uptake by red-seed tree seedlings, and (ii) the LED light spectrum can generate a combined effect of growth and biomass promotion in addition to the intensive regime. 


\section{Materials and Methods}

\section{Plant material}

Red-seed tree seeds were supplied by Research Institute of Subtropical Forestry, Chinese Academy of Forestry from a seed source in Anyue County (29 $43^{\prime}$ N, $105^{\circ} 25^{\prime}$ E), Sichuan province, China. Seeds were transported to the Laboratory of Combined Manipulations of Illumination of Fertility on Plant Growth (Zhilunpudao Agric. S\&T Ltd., Changchun, China) and soaked in distilled water for $17 \mathrm{~h}$. A potassium (K) permanganate solution $(0.5 \%, \mathrm{w} / \mathrm{w})$ was used to sterilize seeds for $0.5 \mathrm{~h}$. Seeds were treated by bactericide $(0.4 \%$, $\mathrm{w} / \mathrm{w})$ and moved to a chamber for incubation at $30 \pm 4^{\circ} \mathrm{C}$ with relative humidity $(\mathrm{RH})$ of $70 \%$. About three months later all seeds swelled and germinated to show epicotyls. Germinant seeds were sown into growing media (55\% peat, 20\% spent-mushroom residue, $25 \%$ perlite; Mashiro-Dust ${ }^{\mathrm{TM}}$, Zhiluntuowei A\&F S\&T Ltd., Changchun, China) in planting plugs (top diameter, $7 \mathrm{~cm}$; height, $13 \mathrm{~cm}$ ) embedded within plastic cultural trays. This growing container had the same size as those in studies on larch (Zhao et al., 2019), Buddhist pine (Wei et al., 2017; Xu et al., 2019), and valued shrubs (Aralia elata) (Wei et al., 2020). The volume of our container was $0.5 \mathrm{~L}$ which was lower than that in the minimum pot but met the recommendation for the culture of red-seed tree seedlings (Chu et al., 2020). Basic properties of the substrate included $120 \mathrm{mg} \mathrm{kg}^{-1}$ $\mathrm{NH}_{4}{ }^{+}-\mathrm{N}, 140 \mathrm{mg} \mathrm{kg}^{-1} \mathrm{NO}_{3}^{-}-\mathrm{N}$ and $360 \mathrm{mg} \mathrm{kg}^{-1}$ soluble phosphorus (P). More details about chemical properties of growing media can found in Wei et al. (2020). The temperature was maintained within $15-36^{\circ} \mathrm{C}$ while $\mathrm{RH}$ ranged from $28-99 \%$.

\section{Fertilizer regime}

One week after the emergence of the first pair of leaves, seedlings were subjected to EF. Two application rates were employed. A low rate of $160 \mathrm{mg} \mathrm{N}$ plant $^{-1}$ was assigned to the conventional regime. This rate was close to the lowest amount ( $180 \mathrm{mg} \mathrm{N}$ plant $^{-1}$ ) in CRF delivered to red-seed tree seedlings (Chu et al., 2020), but met the recommended optimum-rate (150-175 $\mathrm{mg} \mathrm{N}$ plant $^{-1}$ ) for the culture of Quercus ilex seedlings (Uscola et al., 2015). Another high rate of $600 \mathrm{mg} \mathrm{N}$ plant ${ }^{-1}$ was assigned to the intensive regime. This high rate was adapted from the normal one from the culture of another vulnerable species of Fragrant rosewood (Dalbergia odorifera) (Li et al., 2017; Li et al., 2018). This high rate also fell in the range of the highest rates (540-720 mg N plant ${ }^{-1}$ ) of CRF application for red-seed tree seedlings (Chu et al., 2020). Initial N content $\left(N_{S}\right)$ in seedlings was set to $1.4 \mathrm{mg} \mathrm{plant}^{-1}$, which was necessary to calculate the coefficient $(r)$ in EF model (Wei et al., 2013). Seedlings were fertigated once a week and a total of 16 applications were delivered. Thereafter, $r$ was calculated to be 0.2967 for the delivery of $160 \mathrm{mg} \mathrm{N}$ plant $^{-1}$ and $0.3789 \mathrm{for} 600 \mathrm{mg} \mathrm{N}_{\text {plant }}{ }^{-1}$ according to the equation of Duan et al. (2013). Nutrients were delivered with chemical solutions of ammonium sulfate $\left(\left[\mathrm{NH}_{4}\right]_{2} \mathrm{SO}_{4}\right)$ and monopotassium phosphate $\left(\mathrm{KH}_{2} \mathrm{PO}_{4}\right)$ (N-P-K, 12-9-12).

\section{Light spectra}

Seedlings started to receive lighting from the first day when over $80 \%$ of seedlings had shown their first pair of leaves. Half of the trayed seedlings were subjected to HPS lighting and the other half to LED lighting. The two light environments were split by a black-out fabric. In the HPS spectrum treatment, two lamps were fixed to a height of $60 \mathrm{~cm}$ above the ground and $45 \mathrm{~cm}$ to the tip of seedling shoots. LED light was given by a panel with diodes in red (600 to $700 \mathrm{~nm}$ ), blue ( 400 to $500 \mathrm{~nm}$ ), and green (500 to $600 \mathrm{~nm}$ ) that combined supplied lights with the spectrum of $85 \%$ red, $10 \%$ green, and $5 \%$ blue light wavelengths $15 \mathrm{~cm}$ beneath the panel. Both illuminators emitted lights with photosynthetic photon flux density (PPFD) of 70-77 $\mu \mathrm{mol} \mathrm{m} \mathrm{m}^{-2} \mathrm{~s}^{-1}$ and intensity of 2100-2700 Lx. More details about lighting condition and spectra characteristics can be found in Wei et al. (2020). 


\section{Seedling culture and sampling}

A total of 16 seedlings were raised in plugs of one tray with a $14 \mathrm{~cm} \times 14 \mathrm{~cm}$ spacing. This equals to 8.82 $\times 10^{3}$ individuals $\mathrm{ha}^{-1}$. Seedlings were watered by a sub-irrigation system which was achieved by soaking from a tank (Wei et al., 2020). EF was applied through 16 deliveries; seedlings were sampled in the $17^{\text {th }}$ week after fertilizing began. Eight seedlings were randomly chosen and excavated from planting plugs in one tray. Height and root-collar diameter (RCD) were measured for the aerial parts of all eight sampled seedlings. Root stocks were kept intact to keep fine roots undamaged as much as possible. Roots were rinsed with distilled water to remove all adherent substrates. Cleaned seedlings were divided into two groups with one half used for measuring leaf area, biomass, nutrient concentration, and carbohydrate concentration, and the other half used for measuring chlorophyll, soluble protein, antioxidant enzyme activity, and nutrient assimilation enzyme activity.

\section{Chemical analysis}

Leaves were excised from the first half of four seedlings then seedlings were divided into stems and roots. Leaves were kept in moist towels until scanned and measured for projected area using digital analysis method (Xu et al., 2019). Samples of leaves, stem, and root were dried in an oven at $70 \pm 2{ }^{\circ} \mathrm{C}$. Dried samples were measured for dry matter biomass weight, ground, and used to determine $\mathrm{N}$ and $\mathrm{P}$ concentrations (Wei et al., 2020) and soluble sugars and starch concentrations (Zhao et al., 2020). Leaves of the other half of the four seedlings were excised and kept in soluble $\mathrm{N}$ until used to determine chlorophyl and soluble protein contents (Zhao et al., 2019) and GS and AP activities (Wei et al., 2020; Zhao et al., 2020). Enzymatic antioxidant assays on superoxidase dismutase (SOD), peroxidase (POD), and catalase (CAT) were performed according to the methods in Hussain et al. (2018).

\section{Statistical analysis}

Data were analyzed using a split-plot design with different light spectra as the main block and fertilizer regime as the sub-block. Each light $\times$ fertilizer combined treatment was replicated three times and assigned as three trays of seedlings. The placement of trays was assigned as the random factor which was rearranged every week after fertigation. SAS software (Ver. 9.4, SAS Institute, Cary, NC, USA) was used to accomplish all statistical analyses. Analysis of variance (ANOVA) was employed using the split-plot model. When the combined effect was detected to be significant, data were analyzed by one-way ANOVA model in response to the combined light $\times$ fertilizer. Results were compared and arranged by Tukey test. The probability of significance was set as 0.05 . Vector analysis was used to evaluate nutritional status according to the method of Salifu and Timmer (2003).

\section{Results}

\section{Seedling growth}

Seedling height and RCD were both significant in response to the interactive effects of light spectra and fertilizer regime (Table 1). Seedlings subjected to the conventional fertilizer rate under LED lighting had the highest height (Figure 1A). Height in seedlings exposed to a high rate of EF in HPS spectrum was the lowest. Root-collar diameter was also highest in seedlings subjected to a low rate of EF in LED spectrum (Figure 1B). Seedlings subjected to an intensive regime in HPS spectrum had lower RCD than those in LED lighting. 
Table 1. Analysis of variance (ANOVA) of fertilizer regime (Fer.), light spectra (Lig.), and their interaction $($ Fer. $\times$ Lig.) on growth, biomass, and nitrogen $(\mathrm{N})$ and phosphorus $(\mathrm{P})$ contents and concentrations in red-seed tree (Ormosia hosiei Hemsley \& E. H. Wilson) seedlings.

\begin{tabular}{|l|c|c|c|c|c|c|}
\hline \multirow{2}{*}{ Parameter } & \multicolumn{4}{|c|}{ Source of variance } \\
\cline { 2 - 7 } & \multicolumn{2}{|c|}{ Fer. } & \multicolumn{2}{c|}{ Lig. } & \multicolumn{2}{c|}{ Fer. $\times$ Lig. } \\
\cline { 2 - 7 } & $F$ value & $P$ value & $F$ value & $P_{\text {value }}$ & $F$ value & $P$ value \\
\hline Height & 68.60 & $<0.0001$ & 35.24 & $<0.0001$ & 35.85 & $<0.0001$ \\
\hline RCD $^{1}$ & 43.72 & $<0.0001$ & 12.97 & 0.0018 & 19.54 & $<0.0001$ \\
\hline Leaf biomass & 40.95 & 0.0002 & 20.42 & 0.0020 & 22.05 & 0.0003 \\
\hline Stem biomass & 15.36 & 0.0044 & 3.25 & 0.1092 & 6.86 & 0.0133 \\
\hline Root biomass & 35.80 & 0.0003 & 9.76 & 0.0141 & 15.96 & 0.0010 \\
\hline R/S ${ }^{2}$ & 6.06 & 0.0392 & 0.67 & 0.4366 & 0.68 & 0.4323 \\
\hline Leaf N content & 34.01 & 0.0004 & 16.63 & 0.0035 & 17.63 & 0.0007 \\
\hline Stem N content & 35.84 & 0.0003 & 3.44 & 0.1007 & 14.84 & 0.0012 \\
\hline Root N content & 19.69 & 0.0022 & 2.20 & 0.1765 & 7.30 & 0.0112 \\
\hline Leaf P content & 12.65 & 0.0074 & 2.08 & 0.1869 & 0.39 & 0.5517 \\
\hline Stem P content & 4.77 & 0.0605 & 0.84 & 0.3868 & 1.87 & 0.2131 \\
\hline Root P content & 8.21 & 0.0210 & 0.51 & 0.4964 & 2.91 & 0.1011 \\
\hline Leaf N concentration & 6.79 & 0.0313 & 2.19 & 0.1775 & 3.51 & 0.0689 \\
\hline Stem N concentration & 98.15 & $<0.0001$ & 0.42 & 0.5351 & 34.09 & $<0.0001$ \\
\hline Root N concentration & 6.88 & 0.0305 & 6.17 & 0.0378 & 4.53 & 0.0389 \\
\hline Leaf P concentration & 6.45 & 0.0348 & 12.78 & 0.0072 & 6.45 & 0.0157 \\
\hline Stem P concentration & 65.31 & $<0.0001$ & 2.74 & 0.1364 & 5.42 & 0.0483 \\
\hline Root P concentration & 59.43 & $<0.0001$ & 23.42 & 0.0013 & 28.13 & 0.0001 \\
\hline
\end{tabular}

${ }^{1} \mathrm{RCD}$, root-collar diameter; ${ }^{2} \mathrm{R} / \mathrm{S}$, root to shoot biomass ratio.
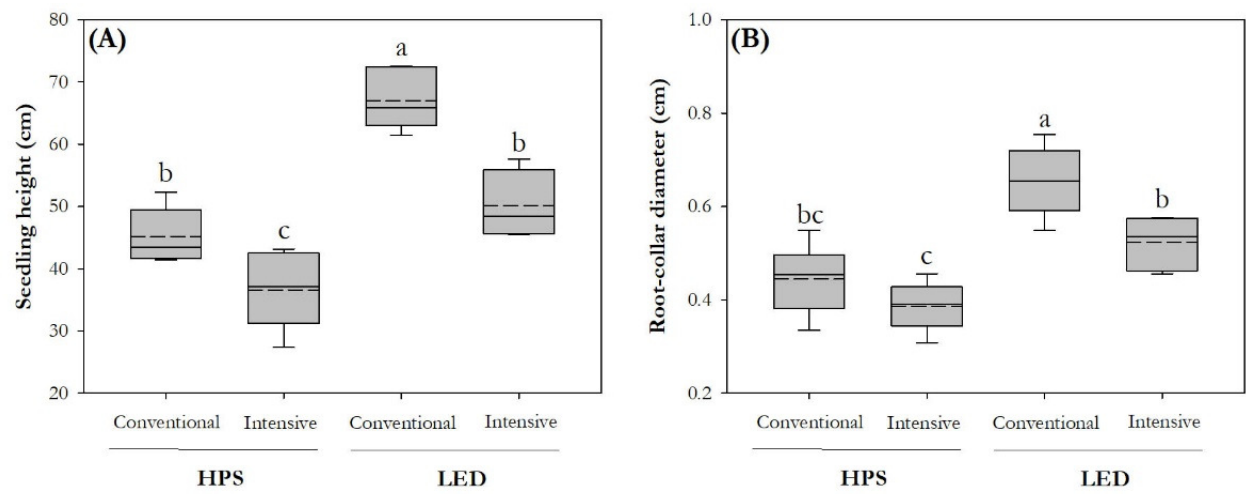

Figure 1. Seedling height (A) and root-collar diameter (B) in red-seed tree (Ormosia hosiei Hemsley \& E. $\mathrm{H}$. Wilson) seedlings subjected to EF at low (conventional) and high (intensive) rates in spectra from highpressure sodium (HPS) lamps and in light-emitting diode (LED) panels

Full lines in whisky-boxes present the medium value and the dashed lines present means. Different letters indicate significant differences $(P<0.05)$ using Tukey test.

\section{Biomass accumulation and nutrient content}

All leaf, stem, and root biomasses were significant when subjected to combined light spectra and fertilizer regime treatments (Table 1). Biomass was greatest in leaves, stem, and root of seedlings subjected to $\mathrm{EF}$ at a low rate in the LED spectrum (Figure 2A). However, the difference of stem biomass was not significant between LED-lighting for seedlings exposed to conventional vs intensive regimes. The LED spectrum resulted in a higher root to shoot biomass ratio $(\mathrm{R} / \mathrm{S})$ than the HPS spectrum $(0.25 \pm 0.05$ and $0.18 \pm 0.03$, respectively). 
Nitrogen content was significant when subjected to combined treatments of fertilizer regime and light spectra (Table 1). Leaf $\mathrm{N}$ content was greatest in seedlings subjected to EF at a low rate in LED lighting (Figure 2B). Stem $\mathrm{N}$ content showed nearly the same difference among treatments, but the difference was not significant between conventional and intensive regimes in the LED spectrum. Root $\mathrm{N}$ content was higher in seedlings subjected to EF at a low rate in the LED spectrum than in seedlings in combined intensive loading and HPS spectrum treatment.

Phosphorus content was significantly different across light spectrum $\times$ fertilizer treatments in leaves (Table 1). Again, seedlings subjected to EF at a low rate in the LED spectrum had higher P content than those subjected to a high rate in the HPS spectrum (Figure 2C). Phosphorus content was not different across combined fertilizer $\times$ light treatments in stem and root (Table 1). However, the light spectrum had a significant main effect on $P$ content in roots. Compared to seedlings subjected to the HPS spectrum $(0.93 \pm 0.21 \mathrm{mg}$ plant '; mean \pm standard deviation, the same below), those in the LED spectrum had higher root $\mathrm{P}$ content $\left(1.43 \pm 0.33 \mathrm{mg}\right.$ plant $\left.{ }^{-1}\right)$.

\section{Nutrient concentration}

Effects of light spectrum and fertilizer regime had a significant combined effect on $\mathrm{N}$ and $\mathrm{P}$ concentrations in most organs except for $\mathrm{N}$ concentration in leaves (Table 1). However, the light spectrum showed a main effect on leaf $\mathrm{N}$ concentration, which was higher in the LED spectrum $\left(13.57 \pm 1.24 \mathrm{mg} \mathrm{g}^{-1}\right)$ than in the HPS spectrum $\left(11.68 \pm 1.47 \mathrm{mg} \mathrm{g}^{-1}\right)$ by $16 \%$ (Figure 3A). Stem $\mathrm{N}$ concentration was higher in seedlings subjected to the two fertilizer regimes in the LED spectrum than in those in the HPS spectrum (Figure 3B). Root $\mathrm{N}$ concentration was higher in seedlings subjected to a high dose of EF in the HPS spectrum than in the low dose and LED combined treatment (Figure 3C). Phosphorus concentration also showed the same response in the two treatments for all three types of organs (Figure 3D-F). In addition, seedlings subjected to the two fertilizer regimes in the HPS spectrum had higher P content in stem than those in the LED spectrum (Figure 3E). Root $\mathrm{P}$ concentration in the low rate and LED spectrum treatment was also lower than that in the low rate plus HPS spectrum treatment (Figure 3F).

\section{Diagnosis of nutritional status}

Compared to EF at a low rate, that at a high rate resulted in a lower level of biomass in both types of light spectra (Figure 4). Leaf $\mathrm{N}$ content declined from the conventional regime to the intensive one and $\mathrm{N}$ concentration also decreased accordingly (Figure 4A). Therefore, seedlings in the intensive regime were characterized with excessive $\mathrm{N}$ accumulation caused by antagonistic translocation. Although the HPS spectrum led to greater relative $\mathrm{N}$ decline from the conventional regime to the intensive regime, seedlings in the LED spectrum showed a significant and greater extent of leaf biomass decline. As a result, it can be concluded that the LED spectrum caused more severe relative $\mathrm{N}$ excess in the intensive regime than the HPS spectrum.

Relative to seedlings subjected to the conventional regime, those in the intensive regime suffered declines of leaf biomass accumulation and $\mathrm{P}$ content but a stimulation of leaf $\mathrm{P}$ concentration in the LED spectrum (Figure 4B). Therefore, the relative $P$ status in the LED spectrum can be characterized as excess $P$ supply caused by toxic accumulation. Otherwise, the relative decline of biomass and $\mathrm{P}$ content and concentration in leaves in the HPS spectrum can be characterized with excess $P$ supply caused by antagonistic translocation (Figure 4B). With regard to the magnitude of vectors and the significant decline of biomass, the LED spectrum was again concluded to result in a more severe $P$ excess when under an intensive fertilizer regime. 

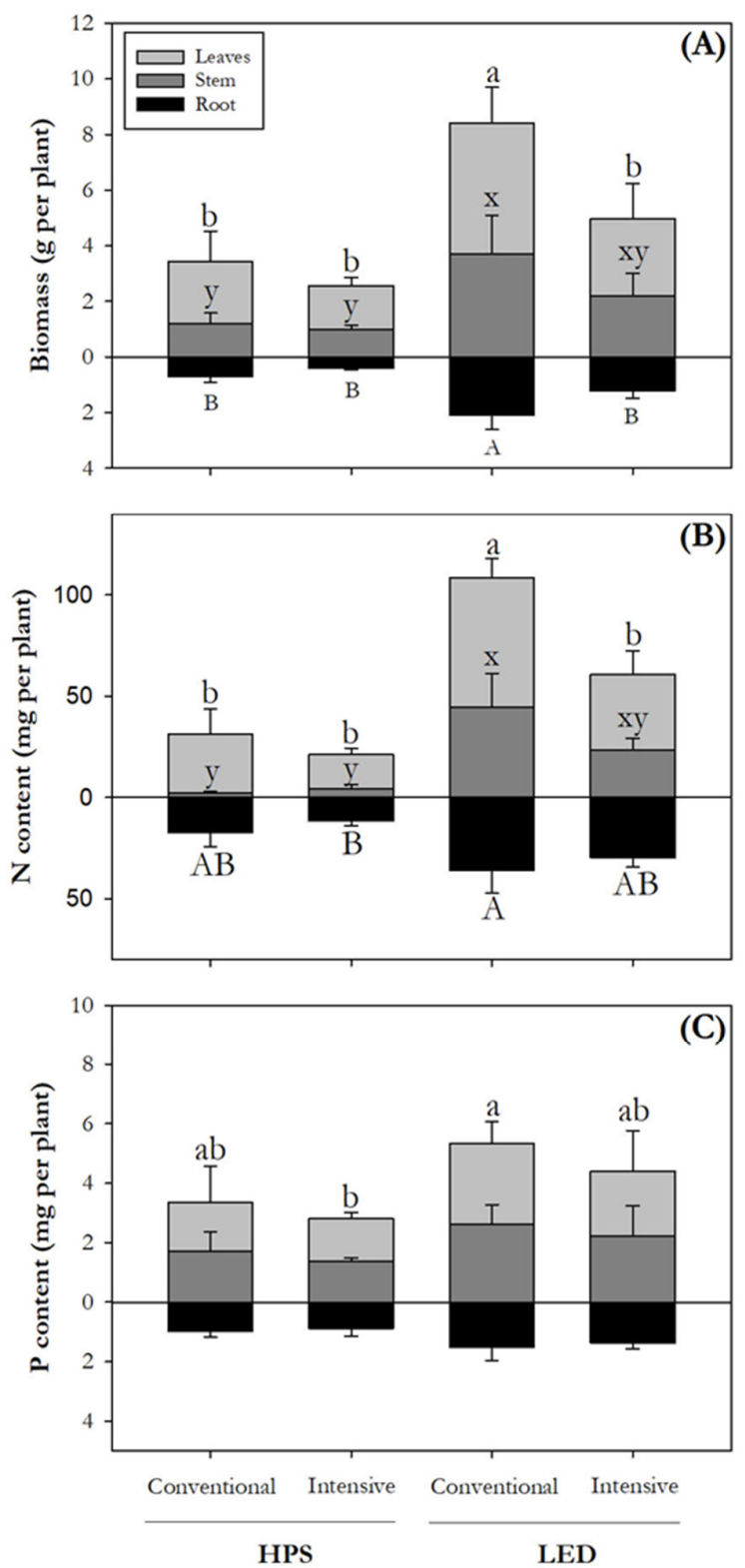

Figure 2. Biomass accumulation (A) and nitrogen (N) and phosphorus (P) contents (B and C, respectively) in leaves, stem, and root of red-seed tree (Ormosia hosiei Hemsley \& E. H. Wilson) seedlings subjected to $\mathrm{EF}$ at low (conventional) and high (intensive) rates in spectra from high-pressure sodium (HPS) lamps and in light-emitting diode (LED) panels

Error bars present standard deviation. Different letters indicate significant differences $(P<0.05)$ using Tukey test. Lowercase a, b, c letters label difference for leaves; lower-case $\mathrm{x}, \mathrm{y}$, $\mathrm{z}$ letters for stem, and capital letters for root. 

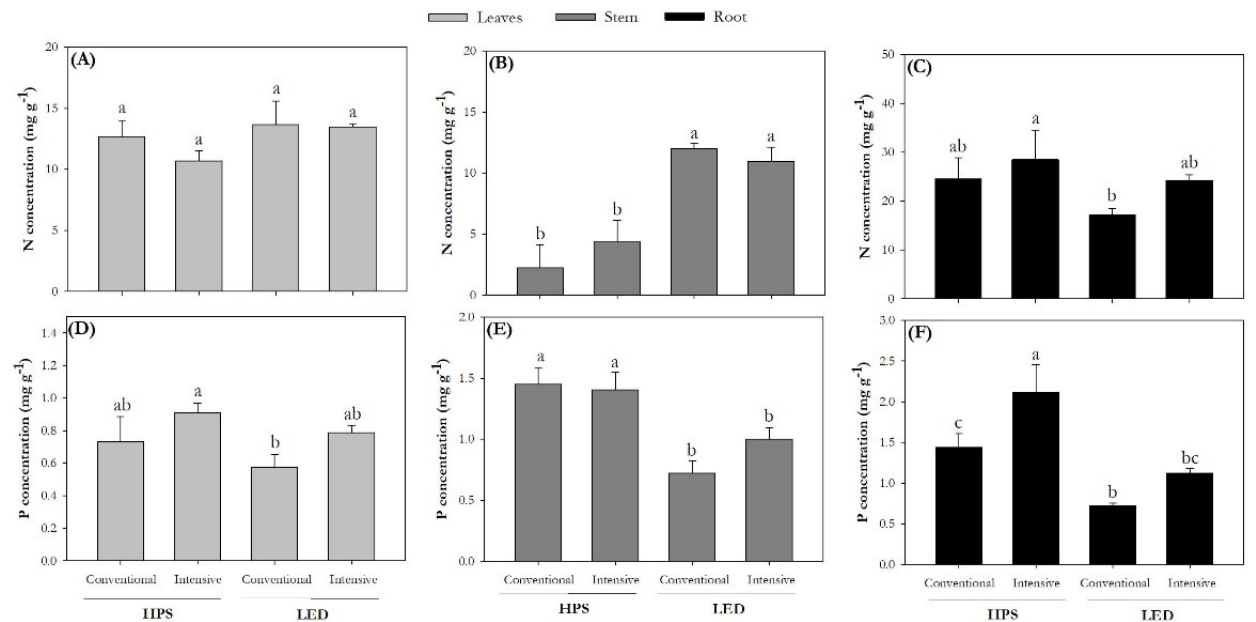

Figure 3. Nitrogen $(\mathrm{N})$ and phosphorus $(\mathrm{P})$ concentrations in leaves (A and D), stem (B and E), and root ( $\mathrm{C}$ and $\mathrm{F}$ ) of red-seed tree (Ormosia hosiei Hemsley \& E. H. Wilson) seedlings subjected to EF at low (conventional) and high (intensive) rates in spectra from high-pressure sodium (HPS) lamps and in lightemitting diode (LED) panels

Error bars present standard deviation. Different letters indicate significant differences $(P<0.05)$ using Tukey test. Lowercase letters label difference for leaves, roman letters for stem, and capital letters for root.
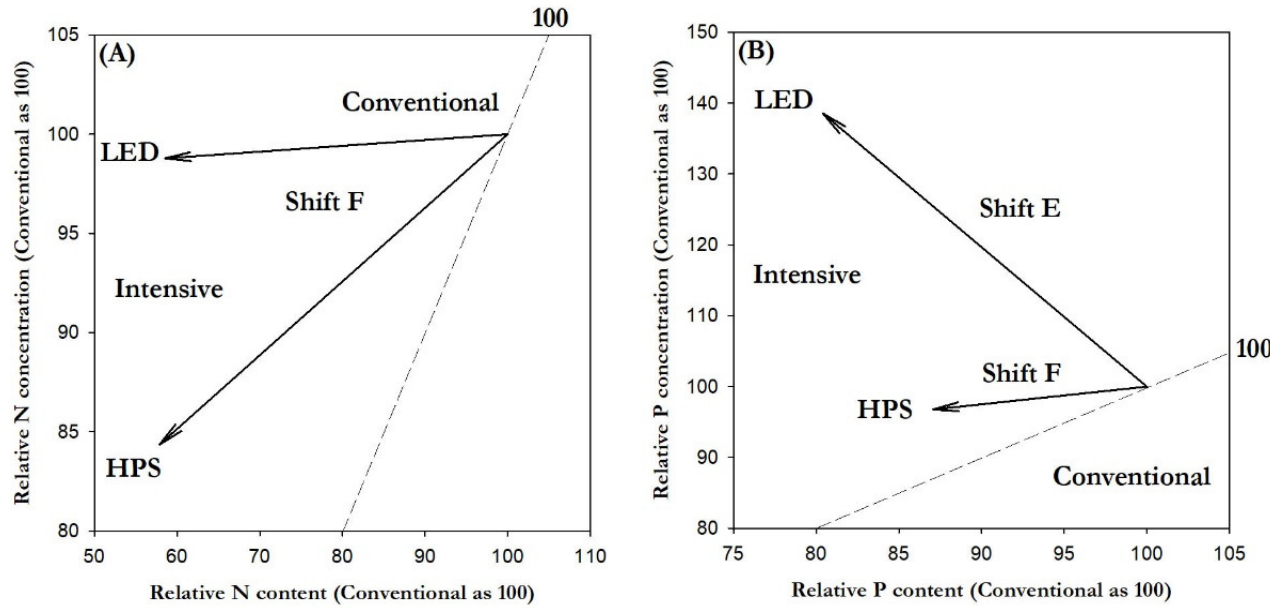

Figure 4. Nomographic analysis of nutrient ( $\mathrm{N}$ and $\mathrm{P})$ content and concentration in addition to biomass accumulation in leaves of red-seed tree (Ormosia hosiei Hemsley \& E. H. Wilson) seedlings subjected to $\mathrm{EF}$ at a low rate (reference) and high rate (object) in contrasting spectra from high-pressure sodium (HPS) and light-emitting diode (LED) illuminators

The establishments of vector shift and adherent interpretation are adapted from Salifu and Timmer (2003). Shift E, excess nutrient supply caused by toxic accumulation; Shift F, excess nutrient supply caused by antagonistic translocation.

\section{Carbohydrate concentration}

No interactive effect of light spectrum and fertilizer regime have been found on soluble sugar and starch concentrations in leaves ( $P=0.7517$ and 0.1808 , respectively) and roots ( $P=0.6671$ and 0.9743 , respectively). $\mathrm{EF}$ at a high rate resulted in higher starch concentration in root compared to that at a low rate (Figure $5 \mathrm{~A}$ ). Accordingly, non-structural carbohydrate (NSC; soluble sugars plus starch) concentration was also higher in the intensive fertilizer regime than in the conventional regime. Soluble sugar concentration in leaves ranged from 126 to $129 \mathrm{mg} \mathrm{g}^{-1}$ and showed no response to any treatments. Soluble sugar concentration showed no 
response to fertilizer regime. However, soluble sugar concentration was higher in the HPS spectrum than in the LED spectrum. NSC concentration was higher in the HPS spectrum than in the LED spectrum.
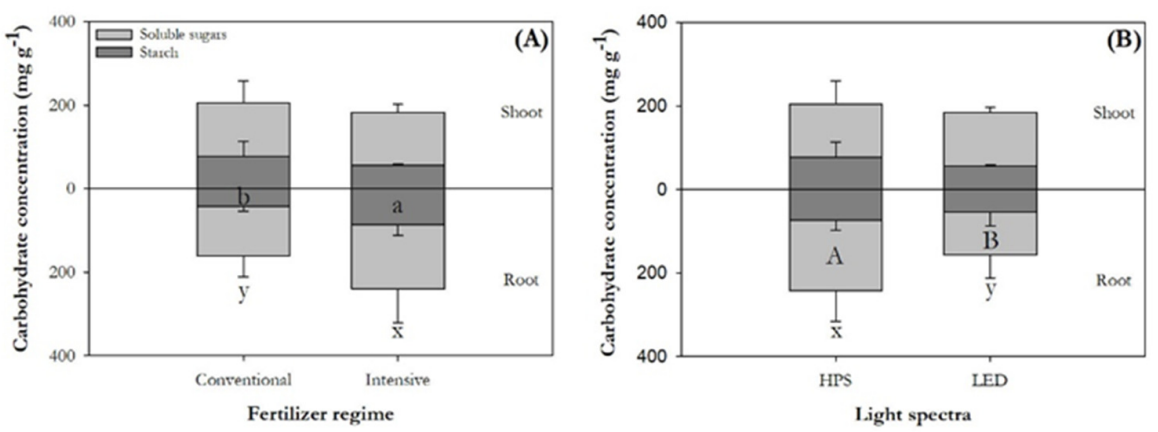

Figure 5. Concentrations of soluble sugars, starch, and non-structure carbohydrate (NSC) in shoot and root parts of red-seed tree (Ormosia hosiei Hemsley \& E. H. Wilson) seedlings subjected to EF at low (conventional) and high (intensive) rates (A) in spectra from high-pressure sodium (HPS) lamps and in light-emitting diode (LED) panels (B)

Error bars present standard deviation. Different letters indicate significant differences $(P<0.05)$ using Tukey test. Lowercase $\mathrm{a}$ and $\mathrm{b}$ letters label difference for the difference of starch, capital letters indicate the difference of soluble sugars, and low-case $\mathrm{x}$ and $\mathrm{y}$ letters indicate the difference of NSC.

\section{Physiological responses}

Light spectrum and fertilizer regime had an interactive effect on chlorophyl a $(P=0.0155)$, chlorophyl $\mathrm{b}$ $(P=0.0419)$, and carotenoid $(P=0.0472)$ concentrations. Seedlings in EF at a low rate in the LED spectrum had higher chlorophyl-a and carotenoid concentrations than seedlings subjected to the conventional regime in the HPS spectrum (Table 2). However, chlorophyl-b concentration was higher in seedlings subjected to the intensive regime than in the conventional regime in the HPS spectrum. Soluble protein concentration was also higher in the conventional regime in the LED spectrum than in the conventional regime in the HPS spectrum $(P=0.0155)$. Leaf area was higher in seedlings subjected to EF at a low rate in the LED spectrum than in seedlings receiving two fertilizer regimes in the HPS spectrum $(P=0.0059)$. Seedlings in the conventional regime in the LED spectrum had higher activity of GS than those in the HPS spectrum receiving two fertilizer regimes $(P=0.0270)$. In contrast, the AP activity was higher in seedlings subjected to $\mathrm{EF}$ at a high rate in the HPS spectrum than in the conventional regime in the LED spectrum $(P=0.0084)$.

Table 2. Chlorophyll, soluble protein, leaf area, glutamine synthetase (GS), and acid phosphate (AP) activities in red-seed tree (Ormosia hosiei Hemsley \& E. H. Wilson) seedlings subjected to conventional and intensive fertilizer regimes under high-pressure sodium (HPS) and light emitting diode (LED) spectra

\begin{tabular}{|l|c|c|c|c|}
\hline \multirow{2}{*}{\multicolumn{1}{|c|}{ Parameters }} & \multicolumn{2}{c|}{ HPS } & \multicolumn{2}{c|}{ LED } \\
\cline { 2 - 5 } & Conventional & Intensive & Conventional & Intensive \\
\hline Chlorophyll a $\left(\mathrm{mg} \mathrm{g}^{-1} \mathrm{DM}\right)$ & $1.16 \pm 0.18 \mathrm{~b}$ & $1.73 \pm 0.22 \mathrm{ab}$ & $2.07 \pm 0.20 \mathrm{a}$ & $1.52 \pm 0.39 \mathrm{ab}$ \\
\hline Chlorophyll b $\left(\mathrm{mg} \mathrm{g}^{-1} \mathrm{DM}\right)$ & $0.73 \pm 0.06 \mathrm{~b}$ & $1.12 \pm 0.25 \mathrm{a}$ & $0.92 \pm 0.01 \mathrm{ab}$ & $0.79 \pm 0.12 \mathrm{ab}$ \\
\hline Carotenoid $\left(\mathrm{mg} \mathrm{g}^{-1} \mathrm{DM}\right)$ & $0.14 \pm 0.02 \mathrm{~b}$ & $0.18 \pm 0.09 \mathrm{ab}$ & $0.34 \pm 0.06 \mathrm{a}$ & $0.22 \pm 0.09 \mathrm{ab}$ \\
\hline Soluble protein $\left(\mathrm{mg} \mathrm{g}^{-1} \mathrm{DM}\right)$ & $1.16 \pm 0.18 \mathrm{~b}$ & $1.73 \pm 0.22 \mathrm{ab}$ & $2.07 \pm 0.20 \mathrm{a}$ & $1.52 \pm 0.39 \mathrm{ab}$ \\
\hline Leaf area $\left(\mathrm{cm}^{2}\right)$ & $0.47 \pm 0.08 \mathrm{~b}$ & $0.40 \pm 0.03 \mathrm{~b}$ & $0.67 \pm 0.08 \mathrm{a}$ & $0.54 \pm 0.07 \mathrm{ab}$ \\
\hline $\mathrm{GS}\left(\mathrm{A} \mathrm{mg}^{-1}\right.$ protein h$\left.^{-1}\right)$ & $0.36 \pm 0.03 \mathrm{~b}$ & $0.03 \pm 0.07 \mathrm{~b}$ & $0.60 \pm 0.09 \mathrm{a}$ & $0.44 \pm 0.13 \mathrm{ab}$ \\
\hline $\mathrm{AP}\left(\mu \mathrm{g} \mathrm{NPP} \mathrm{g}^{-1} \mathrm{FW} \mathrm{min}^{-1}\right)$ & $16.69 \pm 2.77 \mathrm{ab}$ & $21.49 \pm 2.70 \mathrm{a}$ & $10.97 \pm 0.99 \mathrm{~b}$ & $16.12 \pm 3.42 \mathrm{ab}$ \\
\hline
\end{tabular}




\section{Antioxidant response}

No interaction between light spectrum and fertilizer regime was detected for the effect on POD activity $(P=0.1497)$ (Figure 6A). Additionally, the light spectrum did not show any main effect on the POD activity (53-47 mmol min ${ }^{-1} \mathrm{mg}^{-1}$ protein). However, EF at a high rate induced higher POD activity $(58.70 \pm 11.32$ mmol min ${ }^{-1} \mathrm{mg}^{-1}$ protein) relative to a low rate $\left(41.25 \pm 12.82 \mathrm{mmol} \mathrm{min}^{-1} \mathrm{mg}^{-1}\right.$ protein).
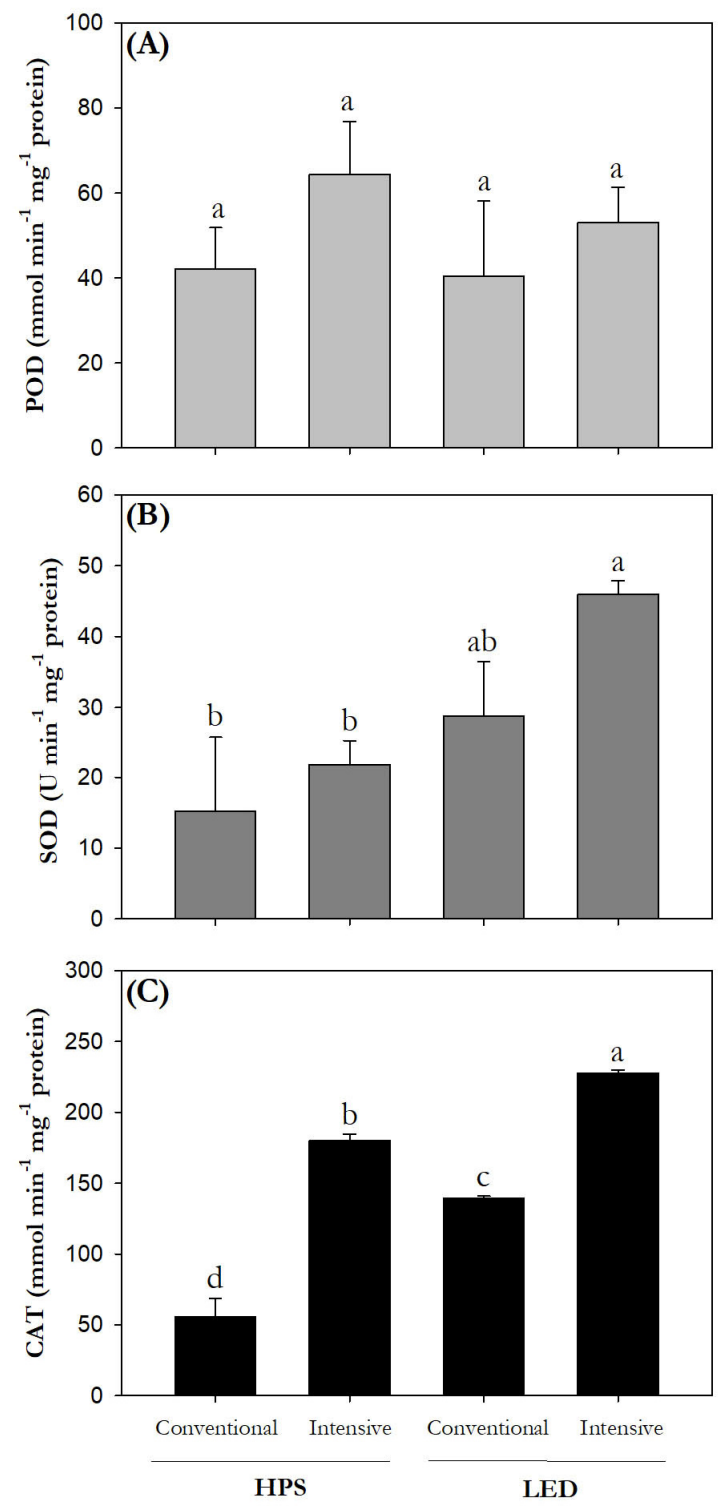

Figure 6. Antioxidative enzyme activity in leaves of red-seed tree (Ormosia hosiei Hemsley \& E. H. Wilson) seedlings subjected to EF at low (conventional) and high (intensive) rates in spectra from highpressure sodium (HPS) lamps and in light-emitting diode (LED) panels

Error bars present standard deviation. Different letters indicate significant differences $(P<0.05)$ using Tukey test. 
The SOD activity was higher in seedlings subjected to EF at high rate in the LED spectrum than in those subjected to both types of fertilizer regimes in the HPS spectrum ( $P=0.0031$ ) (Figure 6B).

Among light spectra and fertilizer treatments, the CAT activity was highest in seedlings subjected to EF in the LED spectrum $(P<0.0001)$ (Figure 6C). Seedlings subjected to EF at a high rate in the HPS spectrum had higher CAT activity than those in the conventional + HPS treatment and in the conventional + LED treatment. Seedlings in EF at a low rate in the HPS spectrum had the lowest CAT activity (Figure 6C).

\section{Discussion}

In our first hypothesis, we expected to promote nutrient uptake by EF at a high rate. This was put forward because the high application rate in the intensive regime of $600 \mathrm{mg} \mathrm{N}$ plant $^{-1}$ fell within empirical cases of culturing tree seedlings in vulnerable species by CRF fertilization ( Li et al., 2017; Li et al., 2018; Chu et al., 2020). However, according to our findings we cannot accept our first hypothesis. The vector analysis indicated symptoms of excess supplies of both $\mathrm{N}$ and $\mathrm{P}$ elements in both spectra. This was characterized by the dual decline of leaf biomass and nutrient $(\mathrm{N}$ and $\mathrm{P})$ content. Therefore, we can confirm that the high rate used in this study was not suitable for the culture of red-seed tree seedlings even though it has been used in CRF fertilization. As Zhu et al. (2016) found, leaching loss cannot be avoided when CRF was used as the source of nutrient supply. Seedlings did not show negative response when subjected to a high dose of CRF because some nutrients may have been lost by leaching. It was necessary to feed seedlings with a greater amount than needed of CRF granules to cover the loss. Although fertigation would result in nutrient loss through leaching (Dumroese et al., 2005), EF can maximize the efficiency of nutrient delivery which covers part of leaching loss. We did not quantify nutrient leaching; hence, we cannot give any confirmative results about the amount of nutrient loss. Future work is suggested to test our conjecture with assessment of both nutrient uptake and leaching loss. The rate of $160 \mathrm{mg} \mathrm{N}$ plant ${ }^{-1} \mathrm{can}$ be recommended to fertilize red-seed tree seedlings through $\mathrm{EF}$. If more clarification is required on a more precise rate for a range of nutritional statuses, a dose-response model could be studied in future work wherein our recommended dose can be assumed as the optimum one (Uscola et al., 2015; Xu et al., 2019).

It was surprising to find that the over-dose of intensive loading can increase root NSC accumulation through promoting root starch translocation. The increase of root starch concentration facing a high stress environment has also been found for subalpine (Brunner et al., 2002) and citrus trees (Yang et al., 2020). Two possible explanations could account for our results. The first is that the toxicity supply broke enzyme activities that were responsible for starch hydrolysis (Devi et al., 2007). The second is that toxicity promoted the conversion from sucrose into starch to fuel stressed roots (Wei and Guo, 2017). Because soluble sugars in root were not affected by fertilizer regime, we agree more with the assumption that the access of starch hydrolysis was broken.

The excess of nutrient supply can also be reflected by shoot growth, which was reduced by the intensive fertilizer regime in the LED spectrum. The decrease of growth is another symptom indicating negative impact from over-dose fertilization (Xu et al., 2019). Stem growth and shoot biomass were not affected by the fertilizer treatment in the HPS spectrum. This means that the HPS spectrum cannot supply a lighting environment that facilitates the variation of shoot growth between fertilizer doses. It was interesting to find that nutrient uptake was also not affected by the EF treatment in the HPS spectrum. This suggests that the failure of shoot growth in response to fertilizer regime from lighting by the HPS was partly caused by low uptake. As the intensive loading was identified to cause nutrient excess, it can be surmised that the HPS spectrum "weakened" this negative effect by diminishing the effect of a high dose. Otherwise, the LED spectrum caused stimulation to it because most responses in growth, biomass, and nutrient uptake were differentiated. The LED spectrum was also found to promote tree seedling growth relative to the HPS spectrum (Wei et al., 2020; Wei et al., 2020), as well as promoting nutrient uptake and utilization compared to the HPS spectrum when the rhizosphere 
nutrients are satisfied by roots (Luo et al., 2020; Wei et al., 2020). Our results supplemented this judgement with new findings that the LED spectrum can also aggravate the symptom of excess nutrient supply. Therefore, we can accept our second hypothesis.

In the LED spectrum, the low-rate-EF provided seedlings with higher ability of photosynthesis and $\mathrm{N}$ assimilation. Enhanced syntheses in pigment and protein are the result of promotion on $\mathrm{N}$ uptake and assimilation in tree seedlings in the LED spectrum (Apostol et al., 2015; Wei et al., 2020). These changes suggest promoted photosynthesis in the LED spectrum which has also been reported on Buddhist pine (Luo et al., 2020) and coniferous seedlings (Apostol et al., 2015). Increased leaf area under LED lighting is the precondition to enlarge project area of the photobiological device and the subsequent promotion of photosynthetic rate. Increased leaf area in the LED spectrum compared to the HPS spectrum has also been found on bedding and vegetable plants (Poel and Runkle, 2017). Results about the AP activity concur with those about $\mathrm{P}$ concentration in seedling organs. Plant $\mathrm{P}$ concentration was found to have a positive relationship with soluble sugar concentration (Zhao et al., 2020). Our P results were in accordance with soluble sugar concentration, both of which suggest that the HPS spectrum would be more beneficial for P uptake and soluble sugar synthesis.

The formation of reactive oxygen species (ROS) may be prevented by an antioxidant system with POD, SOD, and CAT working as ROS-scavenging compounds. We did not find significant difference of POD activity either among combined treatments or between light spectra. This disagreed with previous findings ( $\mathrm{He}$ et al., 2015). Seedlings with a high rate of EF showed higher POD activity, suggesting a negative effect of nutrient excess. Both activities of SOD and CAT were higher in the LED spectrum and the intensive fertilizer regime than in seedlings subjected to the HPS spectrum. These results suggest that a high rate caused the ROS reaction and the LED spectrum aggravated the negative impact.

\section{Conclusions}

Red-seed tree seedlings show better growth and biomass performances in the LED spectrum than in the HPS spectrum, but the benefit was only apparent in combination with a low rate of EF. Although a high rate was adapted from studies with CRF fertilization to vulnerable seedlings, it was too high for red-seed tree seedlings which caused higher levels of antioxidants. Therefore, a low rate of $160 \mathrm{mg} \mathrm{N}$ plant $\mathrm{t}^{-1}$ is recommended for the culture of red-seed tree seedlings with LED lighting to harvest excellent quality and corresponding physiological responses.

\section{Authors' Contributions}

Conceptualization: XC and ZZ; Data curation: XC; Formal analysis: XC; Funding acquisition: ZC; Investigation: XC and XL; Methodology: XC and ZZ; Project administration: ZC; Resources: ZC; Software: XC; Supervision: ZZ; Validation: XL; Visualization: XC; Writing - original draft: XC; Writing - review and editing: ZZ. Authorship must be limited to those who have contributed substantially to the work reported. All authors read and approved the final manuscript.

\section{Acknowledgements}

Authors thank Prof. Rongzhou Man, from Ontario Forest Research Institute in Canada, for the polishing work and suggestions for the paper. This work was supported by Forestry Science and Technology Cooperation Project between Zhejiang Province and Chinese Academy of Forestry (grant number 2017SY19). 


\section{Conflict of Interests}

The authors declare that there are no conflicts of interest related to this article.

\section{References}

Apostol KG, Dumroese RK, Pinto JR, Davis AS (2015). Response of conifer species from three latitudinal populations to light spectra generated by light-emitting diodes and high-pressure sodium lamps. Canadian Journal of Forest Research 45(12):1711-1719. https://doi.org/10.1139/cifr-2015-0106

Boivin JR, Salifu KF, Timmer VR (2004). Late-season fertilization of Picea mariana seedlings: intensive loading and outplanting response on greenhouse bioassays. Annals of Forest Science 61(8):737-745. https://doi.org/10.1051/forest:2004073

Brunner I, Brodbeck S, Walthert L (2002). Fine root chemistry, starch concentration, and 'vitality' of subalpine conifer forests in relation to soil pH. Forest Ecology and Management 165(1-3):75-84. https://doi.org/10.1016/s0378$1127(01) 00633-8$

Chu XL, Wang XH, Zhang DB, Wu XL, Zhou ZC (2019). Responses of Taxus chinensis and Phoebe chekiangensis seedlings to controlled-release fertilizer in various formulations and application rates. Iforest-Biogeosciences and Forestry 12:254-261. https://doi.org/10.3832/ifor2714-012

Chu XL, Wang XH, Zhang DB, Wu XL, Zhou ZC (2020). Effects of fertilization and container-type on nutrient uptake and utilization by four subtropical tree seedlings. Journal of Forestry Research 31(4):1201-1213. https://doi.org/10.1007/s11676-019-01070-0

Devi R, Munjral N, Gupta AK, Kaur N (2007). Cadmium induced changes in carbohydrate status and enzymes of carbohydrate metabolism, glycolysis and pentose phosphate pathway in pea. Environmental and Experimental Botany 61(2):167-174. https://doi.org/10.1016/j.envexpbot.2007.05.006

Duan J, Xu C, Jacobs D, Ma L, Wei H, Jiang L, Ren J (2013). Exponential nutrient loading shortens the cultural period of Larix olgensis seedlings. Scandinavian Journal of Forest Research 28(5):409-418. https://doi.org/10.1080/02827581.2013.778328

Dumroese RK, Page-Dumroese DS, Salifu KF, Jacobs DF (2005). Exponential fertilization of Pinus monticola seedlings: nutrient uptake efficiency, leaching fractions, and early outplanting performance. Canadian Journal of Forest Research 35(12):2961-2967. https://doi.org/10.1139/x05-226

Hawkins BJ, Burgess D, Mitchell AK (2005). Growth and nutrient dynamics of western hemlock with conventional or exponential greenhouse fertilization and planting in different fertility conditions. Canadian Journal of Forest Research-Revue Canadienne De Recherche Forestiere 35(4):1002-1016. https://doi.org/10.1139/x05-026

He D, Liu YP, Lv BY, Wang Z, Chen Y, He SL (2015). Effect of light from cold cathode fluorescent lamps on tree peony (Paeonia suffruticosa) calli. Journal of Horticultural Science \& Biotechnology 90(4):375-378. https://doi.org/10.1080/14620316.2015.11513197

Hussain S, Khalid MF, Saqib M, Ahmad S, Zafar W, Rao MJ, ... Anjum MA (2018). Drought tolerance in citrus rootstocks is associated with better antioxidant defense mechanism. Acta Physiologiae Plantarum 40(8):10. https://doi.org/10.1007/s11738-018-2710-z

Jacobs DF, Davis AS, Dumroese RK, Burney OT (2020). Nursery Cultural techniques facilitate restoration of Acacia koa competing with invasive grass in a dry tropical forest. Forests 11(11):15. https://doi.org/10.3390/f11111124

Li XW, Chen QX, Lei HQ, Wang JW, Yang S, Wei HX (2018). Nutrient uptake and utilization by fragrant rosewood (Dalbergia odorifera) seedlings cultured with oligosaccharide addition under different lighting spectra. Forests 9(1):15. https://doi.org/10.3390/f9010029

Li XW, Gao Y, Wei HX, Xia HT, Chen QX (2017). Growth, biomass accumulation and foliar nutrient status in fragrant rosewood (Dalbergia odorifera TC Chen) seedlings cultured with conventional and exponential fertilizations under different photoperiod regimes. Soil Science and Plant Nutrition 63(2):153-162. https://doi.org/10.1080/00380768.2017.1312518

Liu X, Wang Z, Xiao Z (2011). Patterns of seed predation and dispersal of an endangered rare plant Ormosia hosiei by Edward's long-tailed rats and Chinese white-bellied rats. Biodiversity Science 19(1):93-96. https://doi.org/10.3724/SP.J.1003.2011.04197 
Luo YQ, Zhao SJ, Tang JY, Zhu H, Wei HX, Cui W, ... Guo P (2020). White-light emitting diodes' spectrum effect on photosynthesis and nutrient use efficiency in Podocarpus macrophyllus seedlings. Journal of Plant Nutrition 43(19):2876-2884. https://doi.org/10.1080/01904167.2020.1798999

Poel BR, Runkle ES (2017). Spectral effects of supplemental greenhouse radiation on growth and flowering of annual bedding plants and vegetable transplants. HortScience 52(9):1221-1228. https://doi.org/10.21273/hortsci12135-17

Salifu KF, Jacobs DF (2006). Characterizing fertility targets and multi-element interactions in nursery culture of Quercus rubra seedlings. Annals of Forest Science 63(3):231-237. https://doi.org/10.1051/forest:2006001

Salifu KF, Timmer VR (2003). Optimizing nitrogen loading of Picea mariana seedlings during nursery culture. Canadian Journal of Forest Research-Revue Canadienne de Recherche Forestiere 33(7):1287-1294. https://doi.org/10.1139/x03-057

Sun H, Vincent MA (2012). Ormosia hosiei. Flora of China. http://www.efloras.org/florataxon.aspx?flora_id=2\&taxon_id=200012244

Uscola M, Salifu KF, Oliet JA, Jacobs DF (2015). An exponential fertilization dose-response model to promote restoration of the Mediterranean oak Quercus ilex. New Forests 46(5-6):795-812. https://doi.org/10.1007/s11056-015-9493-5

Wang Z, Ma LY, Jia ZK, Wei HX, Duan J (2016). Interactive effects of irrigation and exponential fertilization on nutritional characteristics in Populus x euramericana cv. '74/76' cuttings in an open-air nursery in Beijing, China. Journal of Forestry Research 27(3):569-582. https://doi.org/10.1007/s11676-015-0203-0

Wei HX, Chen GS, Chen X, Zhao HT (2020). Growth and nutrient uptake in Aralia elata seedlings exposed to exponential fertilization under different illumination spectra. International Journal of Agriculture and Biology 23(3):644-652. https://doi.org/10.17957/ijab/15.1336

Wei HX, Guo P (2017). Carbohydrate metabolism during new root growth in transplanted Larix olgensis seedlings: posttransplant response to nursery-applied inorganic fertilizer and organic amendment. Iforest-Biogeosciences and Forestry 10:15-22. https://doi.org/10.3832/ifor1988-009

Wei HX, Guo P, Zheng HF, He XY, Wang PJ, Ren ZB, Zhai C (2017). Micro-scale heterogeneity in urban forest soils affects fine root foraging by ornamental seedlings of Buddhist pine and Northeast yew. Urban Forestry \& Urban Greening 28:63-72. https://doi.org/10.1016/j.ufug.2017.10.006

Wei HX, Hauer RJ, Chen GS, Chen X, He XY (2020). Growth, nutrient assimilation, and carbohydrate metabolism in Korean pine (Pinus koraiensis) seedlings in response to light spectra. Forests 11(1):18. https://doi.org/10.3390/f11010044

Wei HX, Ren J, Zhou JH (2013). Effect of exponential fertilization on growth and nutritional status in Buddhist pine (Podocarpus macrophyllus Thunb. D. Don) seedlings cultured in natural and prolonged photoperiods. Soil Science and Plant Nutrition 59(6):933-941. https://doi.org/10.1080/00380768.2013.864957

Wei HX, Xu CY, Ren J, Ma LY, Duan J, Jiang LN (2013). Newly transplanted Larix olgensis Henry stock with greater root biomass has higher early nitrogen flux rate. Soil Science and Plant Nutrition 59(5):740-749. https://doi.org/10.1080/00380768.2013.816977

Wei HX, Zhao HT, Chen X, He XY (2020). Secondary metabolites, carbohydrate accumulation, and nutrient uptake in Aralia elata (Miq.) Seem seedlings exposed to shoot cutting and different LED spectra. Acta Physiologiae Plantarum 42(11):15. https://doi.org/10.1007/s11738-020-03149-2

World Conservation Monitoring Centre (1998). The IUCN Red List of Threatened Species. 1998: e.T32432A9706557. https://dx.doi.org/10.2305/IUCN.UK.1998.RLTS.T32432A9706557.en

Xu L, Zhang X, Zhang DH, Wei HX, Guo J (2019). Using morphological attributes for the fast assessment of nutritional responses of Buddhist pine (Podocarpus macrophyllus Thunb. D. Don) seedlings to exponential fertilization. PLoS One 14(12):14. https://doi.org/10.1371/journal.pone.0225708

Yang TY, Qi YP, Huang HY, Wu FL, Huang WT, Deng CL, Yang LT, Chen LS (2020). Interactive effects of pH and aluminum on the secretion of organic acid anions by roots and related metabolic factors in Citrus sinensis roots and leaves. Environmental Pollution 262:10. https://doi.org/10.1016/j.envpol.2020.114303

Zhang R, Zhou Z, Du K (2012). Genetic diversity of natural populations of endangered Ormosia hosiei, endemic to China. Biochemical Systematics and 40:13-18. https://doi.org/https://doi.org/10.1016/j.bse.2011.09.005

Zhao J, Chen X, Wei HX, Lv J, Chen C, Liu XY, Wen Q, Jia LM (2019). Nutrient uptake and utilization in Prince Rupprecht's larch (Larix principis-rupprechtii Mayr.) seedlings exposed to a combination of light-emitting diode 
spectra and exponential fertilization. Soil Science and Plant Nutrition 65(4):358-368. https://doi.org/10.1080/00380768.2019.1631715

Zhao Y, Wang Z, Xu SJ, Li YJ, He CX (2020). Nutrient assimilation and utilization in korean pine (Pinus koraiensis) seedlings exposed to exponential fertilization under contrasting spectra. Communications in Soil Science and Plant Analysis 51(18):2414-2428. https://doi.org/10.1080/00103624.2020.1836210

Zhu KY, Liu HC, Wei HX, Zhou JH, Zou QC, Ma GY, Zhang JQ (2016). Prediction of nutrient leaching from culture of containerized Buddhist pine and Japanese maple seedlings exposed to extended photoperiod. International Journal of Agriculture and Biology 18(2):425-434. https://doi.org/10.17957/ijab/15.0108

OPEN ACCESS

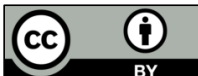

The journal offers free, immediate, and unrestricted access to peer-reviewed research and scholarly work. Users are allowed to read, download, copy, distribute, print, search, or link to the full texts of the articles, or use them for any other lawful purpose, without asking prior permission from the publisher or the author.

License - Articles published in Notulae Botanicae Horti Agrobotanici Cluj-Napoca are Open-Access, distributed under the terms and conditions of the Creative Commons Attribution (CC BY 4.0) License.

(c) Articles by the authors; UASVM, Cluj-Napoca, Romania. The journal allows the author(s) to hold the copyright/to retain publishing rights without restriction. 